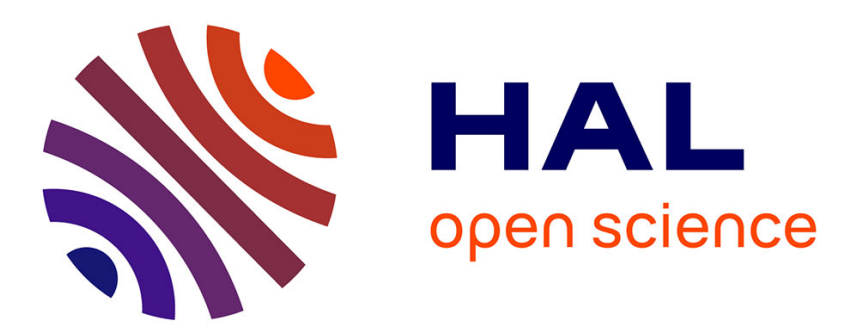

\title{
Miniaturized 3D gas sensors based on silicon nanowires for ppb range detection
}

\author{
Brieux Durand, Aurélie Lecestre, Philippe Menini, Guilhem Larrieu
}

\section{To cite this version:}

Brieux Durand, Aurélie Lecestre, Philippe Menini, Guilhem Larrieu. Miniaturized 3D gas sensors based on silicon nanowires for ppb range detection. IEEE Nanotechnology Materials and Devices Conference (NMDC 2016), Oct 2016, Toulouse, France. pp.1-2, 10.1109/NMDC.2016.7777098 . hal02046543

\section{HAL Id: hal-02046543 https://hal.science/hal-02046543}

Submitted on 26 Feb 2019

HAL is a multi-disciplinary open access archive for the deposit and dissemination of scientific research documents, whether they are published or not. The documents may come from teaching and research institutions in France or abroad, or from public or private research centers.
L'archive ouverte pluridisciplinaire HAL, est destinée au dépôt et à la diffusion de documents scientifiques de niveau recherche, publiés ou non, émanant des établissements d'enseignement et de recherche français ou étrangers, des laboratoires publics ou privés. 


\title{
Miniaturized 3D gas sensors based on silicon nanowires for ppb range detection
}

\author{
Brieux DURAND, Aurélie LECESTRE, Philippe MENINI and Guilhem LARRIEU
}

LAAS-CNRS, Université de Toulouse, CNRS, UPS, Toulouse, France

\begin{abstract}
Here, we reported 3D devices implemented on silicon nanowires (SiNW) for chemical gas sensing, working at room temperature and in presence of moisture or interfering gas. This sensor combines for the first time high sensibility, selectivity, reversibility, low-power consumption and reliability in real condition. In addition the sensors are miniaturized and develop through a cost effective and large scale approach.
\end{abstract}

\section{INTRODUCTION}

Current trends go towards embedded multifunction systems. The most notable case is the evolution of mobile phones which resulted the smartphone: a "tool" with many uses where new sensors are integrated to add new functionalities. In that context, gas sensors would be implemented in order to monitor, during all day long, the air quality in polluted urban environments as the concentration of nitrogen dioxide $\left(\mathrm{NO}_{2}\right)$, or detect domestic gas leaks. However this requires a reorientation of the sensor industry towards components more and more miniaturized to reduce weight, size, power consumption and price. Currently commercial sensors use a metal oxide as sensitive layer on a micro hotplate technology. These devices are relatively large $\left(\approx 1-10 \mathrm{~mm}^{2}\right)$ and require high power consumption for supplying the heater ( $\mathrm{mW}$ range). In addition, they demonstrate low selectivity and sensitivity to high concentrations of gas $(>1 \mathrm{ppm})$, out of step with the recommendations of the various environmental agencies to long period exposure thresholds (50 ppb $\mathrm{NO}_{2}$ [1]). In that context, the integration of $1 \mathrm{D}$ nanostructures, thanks to their high ratio surface/volume, have been proposed to improve the sensitivity and detection limit [2], [3]. However, despite numerous studies of nanowire devices, any demonstration presents satisfactory operation [4], [5] at very low concentrations. Here, we propose a 3D sensor architecture based on silicon nanowires networks of (Figure 1). The 3D configuration improves the free surface for gas adsorption in order to enhence the sensitivity, and decrease the detection limit.

\section{DEVICE FABRICATION}

This approach is compatible with silicon processing using conventional microelectronics tools, allowing the potential co-integration of these sensors with CMOS devices. The transduction is based on resistor configuration where the nanowires bridge the positive and negative electrodes to allow current flow. The device conductance change is monitored.

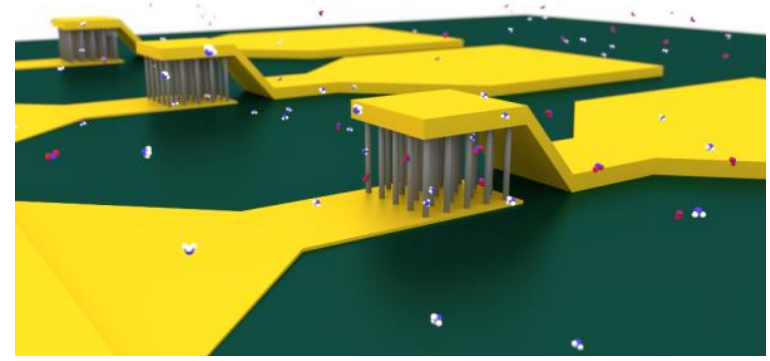

Figure 1: Illustration of the $3 D$ sensor architectures implemented on vertical $N W$ arrays.

The fabrication process is large scale, reproducible and straightforward, and can be summarized in 3 steps: (i) firstly the nanowire networks patterning, (ii) secondly the bottom electrical contacts fabrication, and (iii) finally the top contacts structuration. A top-down approach has been developed (Figure 2.a-e) to perfectly control all the parameters of NW networks (diameter, height, spacing and the numbers of nanowires...).

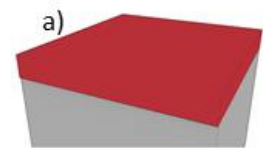

d)
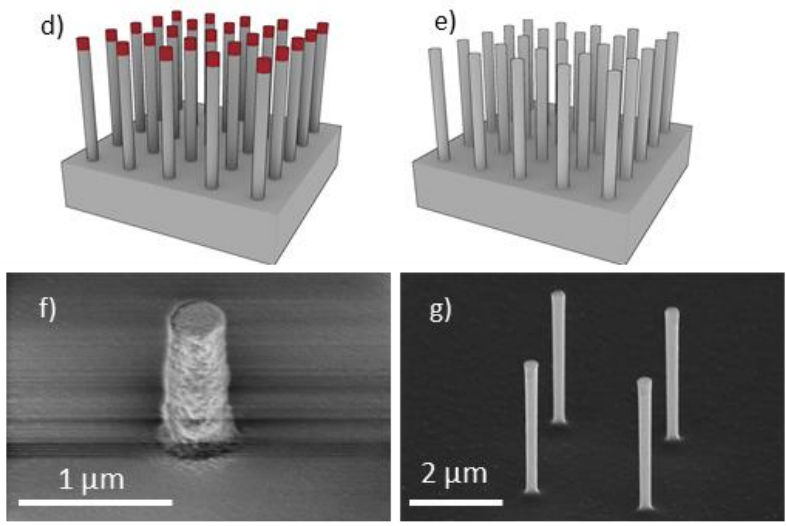

Figure 2: a)-e) Top-down fabrication of vertical nanowires network, SEM pictures off) a resist nanodot and $g$ ) nanowires 
An approach combining photolithography, plasma etching and sacrificial oxidation is developed to pattern the vertical nanowire networks. The first step consists of substrate patterning by photolithography (i-line stepper), to achieve array of resist nanodots (Figure 2.a-c, f). Then the patterns are transferred into the bulk silicon by deep reactive ionic etching (DRIE) (Figure 2.d). Finally remaining resist is stripped and a sacrificial oxide layer is grown to tune precisely the nanowire diameter (Figure 2.e, g).

The device is composed of two symmetrical aluminum contacts at each end of the NWs. The top contact is obtained by an "air bridge" approach of allowing the definition of a three-dimensional connection to the NW top (Figure 3). For the top and bottom contacts, a standard etch-back process is used. However for the top contact, a sacrificial material is employed to connect only the top of the nanowires, leaving the rest of the surface available to react with gases.

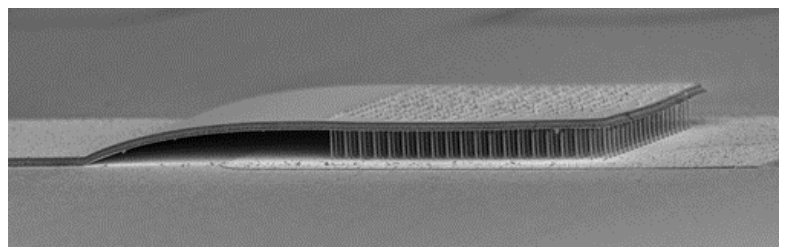

Figure 3: SEM picture of the sensor : a side view of one array of vertical silicon nanowires, contacted electrically by an air-bridge structure

\section{RESULTS AND DISCUSSION}

Under controlled atmosphere, the device demonstrates excellent gas sensing performances. A typical gas response curve is presented in Figure 4. When $\mathrm{NO}_{2}$ is injected, the resistance of the sensor decreases, but when the gas injection stops, the resistance returns to the base-line. The sensor recovery occurs naturally at room temperature, and does not require specific conditions such as UV illumination [4] or flushing [5]. For ammonia, an opposite response was observed: the resistance increases, contrary to $\mathrm{NO}_{2}$ case. Moreover the response of carbon monoxide (CO) and propane $\left(\mathrm{C}_{3} \mathrm{H}_{8}\right)$ have been investigated: in both case there are no response of the sensor. This demonstrates the selectivity of the device, by discriminating $\mathrm{NO}_{2}$ and $\mathrm{NH}_{3}$, without being interfered with $\mathrm{CO}$ and $\mathrm{C}_{3} \mathrm{H}_{8}$.

Due to the enhanced adsorption surface conferring by the 3D configuration, extremely low sensibility level has been reached. A very high response (30\%) is obtained at $50 \mathrm{ppb}$ of $\mathrm{NO}_{2}$ (the dilution limit of our test bench), in comparison of the $25 \%$ reached for $200 \mathrm{ppb}$ in [4], indicating that the limit of $\mathrm{NO}_{2}$ detection by our device is greatly below $20 \mathrm{ppb}$.

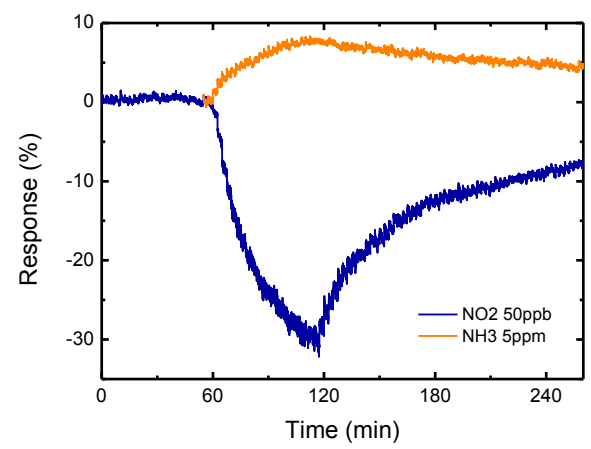

Figure 4: Response of the device to $50 \mathrm{ppb}$ of $\mathrm{NO}_{2}$ (blue) and 5 ppm to $\mathrm{NH}_{3}$ (orange)

In addition, the sensors retain their outstanding performance in real working condition. In particular, we demonstrated that they are not disturbed by the presence of moisture (tested up to $70 \%$ of relative humidity), one of the major drawbacks of metal oxide-based gas sensors. The device is sensitive to humidity and $\mathrm{NH}_{3}$, but in presence of $\mathrm{NO}_{2}$ (even for low concentration) the detection mechanism of $\mathrm{NO}_{2}$ dominates the others mechanisms (moisture and interfering gas).

\section{CONCLUSION}

In summary, we demonstrated record detection of $\mathrm{NO}_{2}$ down to ppb level, using resistor gas sensors based on 3D SiNW networks. This device combines for the first time high sensitivity, selectivity, reversibility, low-power consumption, no poisoning by humidity, reliability, miniaturization, cost effective, large scale and CMOS compatible fabrication, and open the way of new possibilities for integration of unidimensional nanostructures for very sensitive embedded sensors.

\section{REFERENCES}

[1] “Our Nation's Air.” [Online]. Available: http://www3.epa.gov/airtrends/2011/report/fullreport.pdf.

[2] Y. Cui and C. M. Lieber, "Functional nanoscale electronic devices assembled usingsilicon nanowire building blocks," Science, vol. 80, no. 291, pp. 851-853, 2001.

[3] X. Chen, C. K. Y. Wong, C. A. Yuan, and G. Zhang, "Nanowire-based gas sensors," Sens. Actuators B Chem., vol. 177, pp. 178-195, Feb. 2013.

[4] M. C. McAlpine, H. Ahmad, D. Wang, and J. R. Heath, "Highly ordered nanowire arrays on plastic substrates for ultrasensitive flexible chemical sensors," Nat. Mater., vol. 6, no. 5, pp. 379-384, May 2007.

[5] D. Zhang, Z. Liu, C. Li, T. Tang, X. Liu, S. Han, B. Lei, and C. Zhou, "Detection of $\mathrm{NO}_{2}$ down to ppb Levels Using Individual and Multiple In ${ }_{2} \mathrm{O}_{3}$ Nanowire Devices," Nano Lett., vol. 4, no. 10, pp. 1919-1924, Oct. 2004. 